\title{
Çevre Faktörü ve Ergoterapi: Teori ve Model Yaklaşımları
}

\author{
Beyza Aslı BİLSEL*, Selen AYDÖNER ${ }^{* *}$
}

\begin{abstract}
Öz
Ergoterapi alanında model üzerinden inşa edilen bir sistem ile çizilen çerçevenin; terapi ve tedavi metotları planlanırken süreci bütünsel olarak değerlendirme noktasında katkı sağladığı bilinmektedir. Deneyime bağlı plastisitede rol oynayan çevresel zenginleştirme, bilişsel ve davranışsal kapsamlarda bireylerin bağımsızlık sürecine katkı sağlamaktadır. Çevre faktörünü farklı bağlamlarda esas alan ergoterapistler sıklıkla bireylerin yakın çevresine odaklanmaktadır. Çevrenin okupasyonlar üzerindeki önemli etkisi tam olarak anlaşılması önemlidir. Bu derlemede, çevrenin ergoterapideki rolü, kişi ve okupasyonlar ile ilişkisi, insanın dönüşümünde ve zihinsel süreçlerinde çevre faktörünün önemi genel kapsamları ile tartışılmıştır.
\end{abstract}

Anahtar Sözcükler: Çevre, ergoterapi, nöroplastisite, zenginleştirilmiş çevre.

\section{Factor of Environment and Occupational Therapy: Theory and Model Approaches}

\begin{abstract}
The frame is drawn with a system built on the model in the field of occupational therapy; It is thought that it contributes to the holistic evaluation of the process when planning therapy and treatment methods. Environmental enrichment, which plays a role in experiential plasticity, contributes to the independence process of individuals in cognitive and behavioral contexts. Occupational therapists, based on the environmental factors in different contexts, often focus on the immediate environment of individuals. It is important to fully understand the important influence of the environment on occupations. In this review, the role of the environment in occupational therapy, its relationship with the person and occupations, the importance of the environmental factor in human transformation and mental processes are discussed in general terms.
\end{abstract}

Keywords: Environment, occupational therapy, neuroplasticity, enriched environment.

\section{Giriş}

Günümüzde ergoterapinin odak noktası yalnızca bireylerin vücut yapı ve fonksiyonlarındaki bozuklukları ele almanın ötesinde okupasyonlarla birlikte okupasyonel performansı iyileştiren ve katılımı artıran müdahaleleri sağlamaktır¹. Amerikan Ergoterapi Derneği de bu görüşü ergoterapi müdahalelerinde "hayatın yaşandığı çevrelerde insanları desteklenmesi” gerektiğini öne sürerek ifade etmiştir². Ergoterapistin oluşturduğu çevrenin; hastalı̆̆l, bozukluğu veya ihtiyaç talepleri olan bireyler üzerinde önemli etkiye sahip olan bir modalite olduğu öne sürülmüştür. Ayrıca çevre değişikliğinin var olan bireysel problemlerin değiştirilmesindeki rolü de ifade edilmiştir³.

Derleme Makale (Review Article)

Geliş / Received: 14.09.2021 \& Kabul / Accepted: 08.12.2021

DOI: https://doi.org/10.38079/igusabder.995196

* Arş. Gör., İstanbul Gelişim Üniversitesi, Sağlı Bilimleri Fakültesi, Ergoterapi Bölümü, İstanbul, Türkiye,

E-posta: babilsel@gelisim.edu.tr ORCID https://orcid.org/o000-0002-0611-4872

${ }_{* *}^{*}$ Arş. Gör., İstanbul Gelişim Üniversitesi, Sağlık Bilimleri Fakültesi, Ergoterapi Bölümü, İstanbul, Türkiye,

E-posta: saydoner@gelisim.edu.tr ORCID https://orcid.org/o000-0002-0663-1802 
Rehabilitasyon ve toplumsal adaptasyon süreçlerinde terapi ortamının standart ev ve/veya topluluk ortamını yansıtacak şekilde kurulmasının özünde eve dönüşe hazırlanırken bir bakıma çevresel zenginleştirme ve entegrasyon hedeflenmektedir4. Yapılan bir araştırmada kişiye özgü dizayn edilmiş çevrede rehabilitasyon hizmeti alan bireylerin bir kontrol grubuna kıyasla önemli ölçüde daha yüksek fonksiyonel yetenek seviyeleri sergiledikleri görülmüsstür5. Ergoterapinin bir amacı da bireylerin arzu ettiği veya mevcut olan durumdan daha fonksiyonel şekilde okupasyonlara dâhil edilerek sürdürülebilir iyi olma hali ve katılımın desteklenmesidir6 .

Çevre, bir okupasyona katılırken birey için sürecin bir parçası olan fiziksel ve sosyal yönleri ifade eder7. Çevre faktörü, içsel ve dışsal faktörler olarak şekillenir. Duyusal deneyimler aktivitelerin doğasında vardır. Bu bağlamda çevre, insanların bu aktivitelere katılımını kolaylaştırabilir veya kısıtlayabilirr. İnsan, çevre etkeninin pasif alıcısı değildir. Aksine kişiliğinin, tercihlerinin, ilgi alanlarının veya ihtiyaçlarının bir işlevi olarak ortamları yaratmayı, araştırmayı ve dönüştürmeyi seçebilir9. Birey ne kadar sağlıklı ve fonksiyonelse, çevredeki kısıtlayıcı faktörlerden etkilenme olasılığı o kadar azdır. Öte yandan, bireyi kısıtlayan faktörler ne kadar zorlayıcı olursa, engelleyici çevresel faktörlerden etkilenme olasılığı o kadar yüksektir. Bu nedenle çevresel faktörleri bireyin performansını kolaylaştıran veya engelleyen faktörler olarak tanımlanır. Faktörler, "insanların içinde yaşadığı ve yaşamlarını sürdürdüğü fiziksel, sosyal ve davranışsal çevre" olarak açıklanmaktadır ${ }^{10}$.

Ergoterapistin değerlendirme ve müdahale ortamının, hizmet alan perspektifiyle danışanın okupasyonları gerçekleştirmesini etkilediği belirtilmiştir ${ }^{11}$. Bir başka çalışmada ise iyi tasarlanmış bir çevrenin, bireylerin terapi ve hedefleriyle ilişkilendirmeye yardımcı olduğunun görülmesinin yanı sıra bireylerin terapi sürecinde daha motive olduklarını öne sürmüştür7. Bu perspektif ile ergoterapistlere, okupasyonlara katılımın engellendiği veya kısıtlandığı takdirde çevreyi değiştirmeleri önerilmiştir ${ }^{12}$. Araştırmalar bireyin fiziksel, bilişsel ve psikososyal ihtiyaçlarına göre oluşturulmuş çevrelerde, okupasyonlara katılımı teşvik ederek danışanların hayatlarını ve refahlarını geri kazanmalarına yardımcı olabileceğini öngörmüştür ${ }^{13,14}$. Dinamik bir işleyiş planı ile oluşturulan ergoterapi modellerinde bileşenlerden biri olan çevre bağlamı, bu etkileşimin kültürel, kişisel, zamansal ve mekânsal yönlerini ifade eder3. Çevre bir kişinin okupasyonlara katılıp katılamayacağı veya ne derecede katılabileceği konusunda önemli bir rol oynar. Katılım bağlamında ergoterapi modelleri ise çevre faktörünü farklı şekillerde ele alarak bireye uygun müdahale planı oluşturulmasında katkı sağlamaktadır7,15.

\section{Kişi-Çevre-Okupasyon (PEO) ve Kişi-Çevre-Okupasyon-Performans Modeli (PEOP)}

Kişi, çevre ve okupasyon (PEO) bileşenlerini içeren model, bu üç ana faktörün zaman ve mekan içinde yaşam boyu değişim ve etkileşimini temel alan bakış açısı ile geliştirilmiş kişi merkezli bir modeldir ${ }^{16}$ (Şekil 1). Model, bireylerin anlamlı ve amaçl, rol ve sorumluluklarındaki mevcut performans üzerinden engelleyici veya kolaylaştırıcı olarak hareket edebilecek faktörleri analiz etmek ve daha iyi anlamak için hem bireysel hem de makro düzeylerde kullanılmıştır ${ }^{17}$. Ana yapılar arasındaki uyumun anlamlı katılımı arttıracağı, uyumsuzluğun ise katılımı veya okupasyonel performansını tehdit edeceği ileri sürülmektedir. Bu bağlamda çevre faktörü de kişinin günlük yaşamdaki görev performansını dinamik olarak etkilemektedir ${ }^{18}$.

Birey üzerinde birincil odağı fiziksel çevre faktörü etkisinin araştırıldığı bir çalışmada demanslı bir grupta daha düşük bilişsel ve fonksiyonel yeteneklere sahip grubun zenginleştirilmiş çevre ve uyaranların modifiye edildiği bir ortamda yaşadıklarında yaşam kalitelerinin yükseldiği tespit edilmiştir ${ }^{19}$. Bu bağlamda modele göre çevre, kişinin fonksiyonel ve bilişsel becerilerini geliştirebilir ve bireyin sağllk durumundaki düşüşlere uyum sağlamasına izin verebilir ${ }^{20}$. Bunun yanı sıra çoklu duyusal uyaranlarla zenginleştirilmiş bir çevre ile yaşlılar gözlemlendiğinde, 
okupasyonlara katılımda artış, davranış ve ruh hallerinde iyileşme görülmüştür ${ }^{21,22}$. Yani fiziksel, sosyal, kültürel ve sosyoekonomik gibi geniş bir yelpazede incelenen çevre faktörünün niteliği hem bireyin iyi olma haline hem yaşam kalitesinin sürdürülebilirliğine teşvik eder ${ }^{18}$. Kişi ve çevre etkileşiminde çevre faktörü, bireyin tercih ve yeteneklerini yansitmasında rol oynar. İnsan hayatında aile ile kurulan temas ve anlamlı ilişkiler, sınırlı bilişsel yeteneklere sahip kişiler başta olmak üzere bireyin psikososyal iyilik haline katkıda bulunur ${ }^{23}$. Literatürde PEO modeli ile çevre etkileşimini inceleyen bir çalışmada, demanslı bireylerin banyo yapma aktivitesini etkileyen sosyal ve fiziksel çevre kısıtlılıkları değerlendirilmiştir. Sosyal çevre kısıtlılıkları demansh bireylerin banyo yapmada direnç ve ajitasyon göstermesi nedeniyle bakım vereniyle problem yaşaması olarak bildirilirken fiziksel çevre kısıtlılıkları banyoda güvenlik açısından yeterli düzeyde ekipman bulunmaması olarak bildirilmiştir ${ }^{24}$. Benzer olarak PEO modeli çerçevesine dayalı olarak, uyku yönetimi müdahalelerini inceleyen bir çalışma, çevrenin benzersiz etkisini vurgulayarak özellikle fiziksel ve sosyal çevrenin uyku müdahalelerinde göz önünde bulundurulması gereken faktörler olduğunu bildirmiştir ${ }^{25}$.

Şekil 1. Kişi-Çevre-Okupasyon Modeli (PEO).

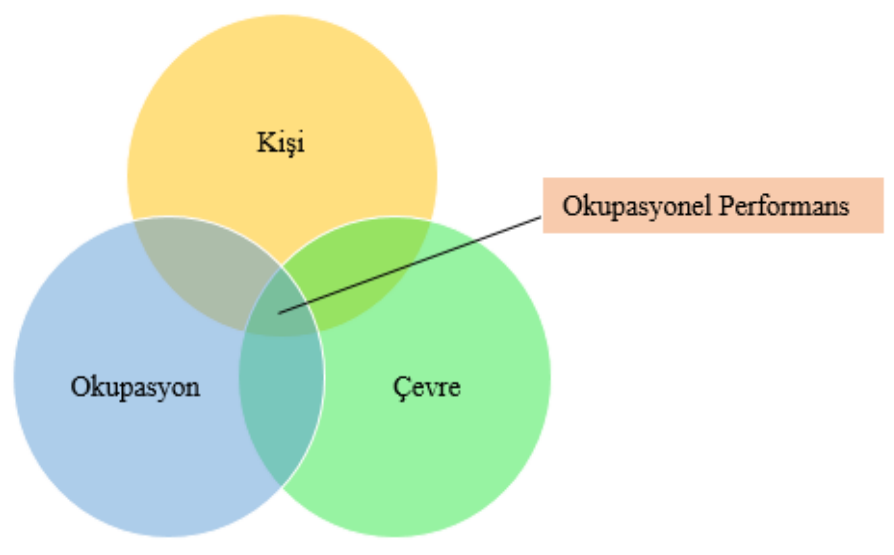

PEOP modeli, PEO ile karşılaştırıldığında interaktif (etkileşimli) ve İşlevsellik, Yetiyitimi ve Sağlığın Uluslararası Sınıflandırması (ICF) ile uyumlu olduğu bilinmektedir. Model bireylerin ve toplumun gerekli ve önemli okupasyonlarını, performanslarını ve çevrede birey için anlamlı katılımı geliştirmede organize edilen kişi merkezli bir model olarak tanımlanmaktadır ${ }^{26}$ (Şekil 2). Model aynı zamanda okupasyonel performansın katılımı kolaylaştırması ile anlam kazanabileceğini vurgular. Kişi ve çevresinin, okupasyon, performans ve katılım ile etkileşimi kişisel (içsel) ve çevresel (dışsal) faktörlerden etkilenmektedir. Kişisel faktörler fizyolojik, bilişsel, spritüal, nörodavranışsal ve psikolojik faktörleri içerirken çevresel faktörler sosyal destek, sosyal ve ekonomik sistemler, kültür ve değerler, yapılı çevre ve teknoloji ve doğal çevreyi kapsar ${ }^{27}$. Kişi ve çevresinin, okupasyon, performans, okupasyonel performans ve katılım ile dinamik ilişkisi iyi olma hali ve yaşam kalitesiyle ilişkilidir ${ }^{26}$. 
Şekil 2. Kişi-Çevre-Okupasyon-Performans Modeli (PEOP).

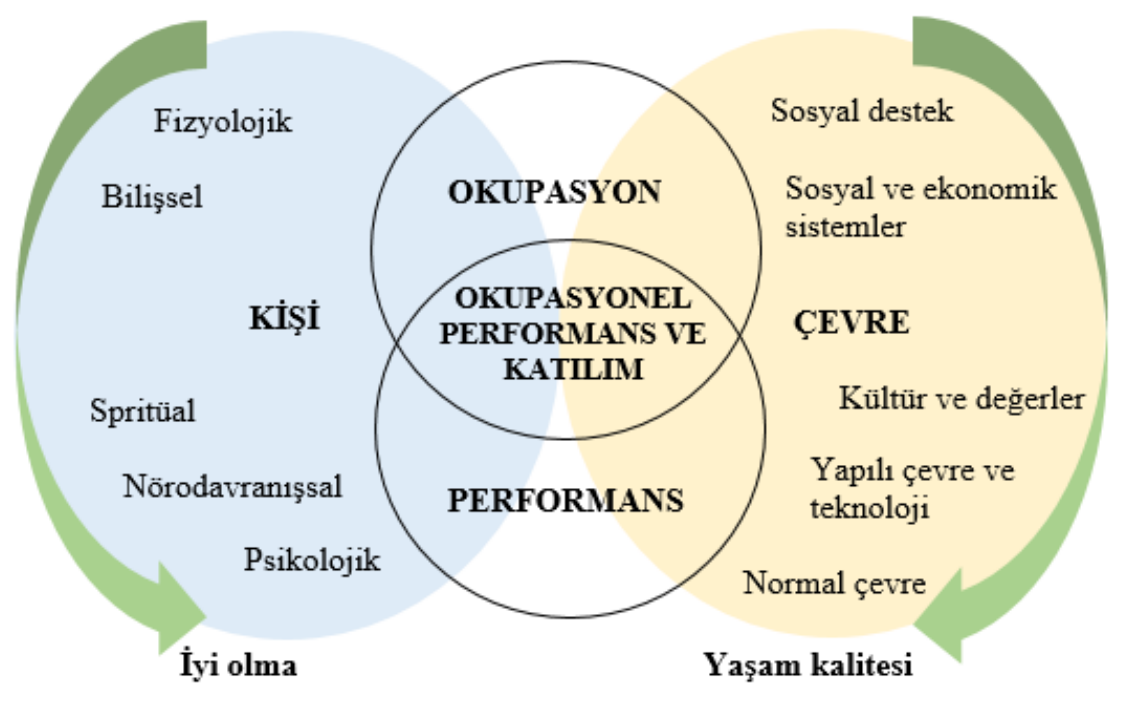

\section{İnsan Okupasyon (Aktivite-Rol) Modeli (MOHO)}

İnsan Okupasyon Modeli (MOHO) okupasyon temelli çerçeve ile ergoterapi dokusuna işlenmiştir. Bireylerin okupasyonlarına ve çevreleriyle ilişkilerine bakmak için tümden gelim (top-down) bir yaklaşım kullanır ${ }^{28}$. Bireyin çevre ile etkileşim içinde ürettiği ve değiştirdiği okupasyonlarını temel alan modelde, okupasyon kavramı, bireylerin rolleri gereği yerine getirmesi gereken sorumluluk ve birey için anlam içeren birey için anlam ifade eden aktivitelerin bütününü tanımlamaktadır. MOHO, okupasyonların gündelik çevrelerde nasıl başlatıldığını, geliştirildiğini ve uygulandığını; okupasyonların, firsatlar ve kaynaklar sağlayan veya onu kısıtlayan çevrelerde gerçekleştiğini vurgular ${ }^{29,30}$. Ayrıca paradigma insan ve okupasyonu anlamak için, içinde bulunduğu fiziksel ve sosyal çevreyi anlamamız gerektiğini vurgular. Sistem, çevreden gelen bilgileri ve gerçekleştirilen eylemin geri bildirimini girdi olarak kabul eder ve ardından sistemin iç kısmından geçer ${ }^{28}$. Bu modelde çevre, okupasyonları hayata geçiren bireylerin içsel özellikleriyle (irade, alışkanlık ve performans kapasitesi) çevre etkileşimin üzerinden "ne yaptığını ve nasıl yaptığına” odaklanır (Şekil 2). 
Şekil 3. İnsan Okupasyon (Aktivite-Rol) Modeli (MOHO)

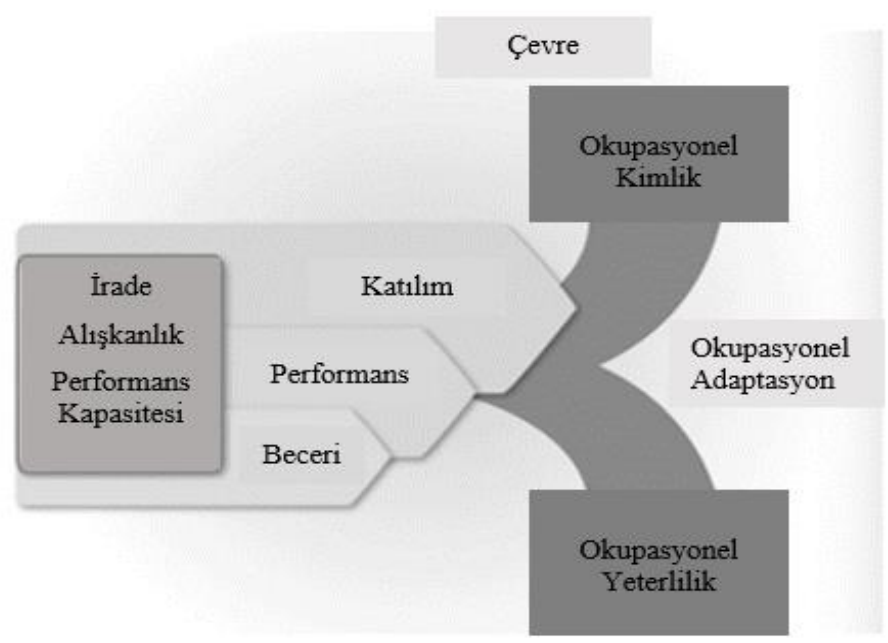

Çevre, bireyin performansına etki ederek bireyin becerilerine, kapasitesine, rolleri algllamasına bağlıdır31. Modelde çevresel etki fırsatlar, kaynaklar, talepler ve kısıtlamalar oluşturan bileşenler olarak algılanır. Okupasyonların karmaşık bir çevrede gerçekleştiği düşünüldüğünde fiziksel ve sosyal çevrenin okupasyonlar üzerinde etkisi büyüktür. Çevreyi oluşturan 4 faktör okupasyonel yapı ve görevler, mekânlar, objeler ve sosyal grup olarak tanımlanmaktadır ${ }^{32}$. Bu faktörler çevrenin sosyal, kültürel, ekonomik, fiziksel ve politik özelliklerini temsil eder (Şekil 4). Mekân kavramı davranışların şekillendiği fiziksel yapı iken obje kavramı insanların etkileşimde bulunduğu cisimler olarak açıllanmaktadır. Okupasyonel yapı ve görevler bir okupasyonu yapmayı karakterize eden belli davranışları kapsar. Sosyal gruplar okupasyonların gerçekleştirildiği yapıları tanımlar. Bu kavramları çerçeveleyen fiziksel çevre, doğal ve insan yapımı mekânları oluştururken sosyal çevre bireyin ait olduğu insanlar topluluğu ve okupasyonel yapılardir ${ }^{2}$.

Şekil 4. MOHO modeli çerçevesinde çevre

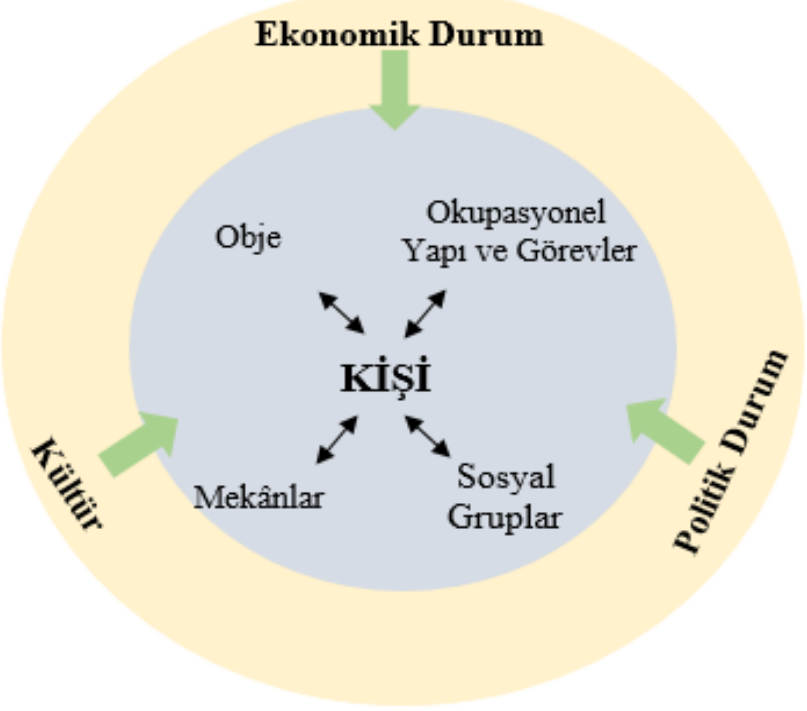


MOHO’ya dayalı ev çevresi modifikasyonlarının engelli bireylerde zaman kullanımı, okupasyonel performans ve aktivite sınırlamaları değerleri üzerine etkisini karşılaştıran bir çalışmada çevresel değişikliklerin insan ve çevre arasındaki etkileşimini artırdığı, çevresel düzenlemelerin engelli bireylerde okupasyonel katılımda zaman kullanımını ve okupasyonları gerçekleştirme yeterliliğini arttırdığını bildirmişlerdir33. AIDS'li bireylerin üretkenlik aktivitelerine katılımını artırmak için MOHO'ya dayalı bir programın etkinliğini değerlendiren başka bir çalışmada bireylerin çevreyle uyumlu katılımını artırmada MOHO modelinin önemini vurgulamışlardır34.

\section{Kanada Okupasyonel Performans ve Katılım Modeli (CMOP-E)}

Bireylerin okupasyonel bağımsızlığına odaklanmış modelin iç kısmı kişi, merkez ise kişinin maneviyatıdır. Bireylerin maneviyatını çevreleyen diğer bileşenler, duygusal, fiziksel ve bilişsel yeteneklerdir. İkinci katman ise okupasyonları temsil ederken, en dış katman fiziksel, sosyal, kültürel ve kurumsal çevre dâhil olmak üzere dış çevreyi temsil eder. Modeldeki üç katman arasındaki etkileşimi okupasyonları yerine getirebilme yeteneği olan okupasyonel performans olarak tanımlanırken, model okupasyonel katılımı irdeleyerek bireysel arzu ve ihtiyaçlara odaklanır35 (Şekil 5). Bir çevrede okupasyona katılan bir kişinin zaman içindeki dinamik deneyimi okupasyonel performans olarak tanımlanır. Bireylerin kendini idame ettirme ve uğraşlarını kapsayan okupasyonlar, kişi ve çevreyi birbirine bağlayan köprü olarak ifade edilmektedir36. Çevre kişilerin dışında oluşan şartlar ve durumlar olarak tanımlanır. Doğal yapı ve inşa edilen maddesel çevre fiziksel çevre; sosyal kurumlar ve uygulamaları, kanunları, karar verme süreçlerini ve diğer kurumsal uygulamalar için kurumsal çevre; toplumda yaşayan kişilerin ilişkilerini, sosyal gruba bağlı ilgiler, değerler, tutum ve inançları kapsayan sosyal çevre; etnik, ırk ve benzeri kültürel farklılıklara bağlı çevre kültürel çevre olarak tanımlanır37.

Obeziteli bireylerin CMOP-E'ye dayalı Okupasyonel performans problemlerini ve engellerini araştıran bir çalışmada bireylerin, okupasyonlara ve kişilik özelliklerine kıyasla çevreleriyle ilişkili olan Okupasyonel performans problemleriyle daha fazla mücadele ettikleri bildirilmiştir ${ }^{3}$.

Şekil 5. Kanada Okupasyonel Performans ve Katılım Modeli (CMOP-E)

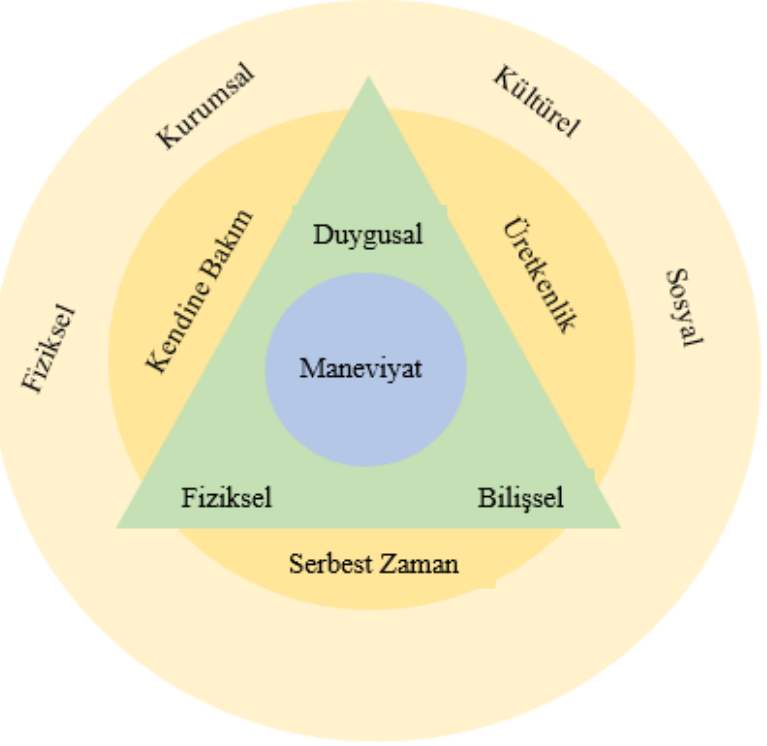




\section{Kawa Modeli}

Japoncada "nehir" anlamına gelen Kawa, bireyin yaşam koşullarının bir resmini oluşturmak için metaforu kullanır. Japon kültüründe nehir, kişisel yaşam için yaygın bir metafordur39,40. Bireyin hayatındaki veya nehirdeki iyi olma hali, güçlü, derin, engelsiz bir akış görüntüsü ile açıklanmaktadır39. Kawa modelinin beş bileşeni vardır: su, kayalar, dalgaların karaya attığı odunlar, nehir yan duvarları ve tabanı ve boşluklar39-41. Su, kişinin yaşam enerjisini veya yaşam akışını; (kayalar ise bireyler tarafından algılanan engelleri ve zorlukları temsil eder ${ }^{40}$. Dalgaların karaya attığı odunlar, bireylerin yaşamını hem olumlu hem de olumsuz yönde etkileyebilecek özellikleri; nehir yan duvarları ve tabanı bireylerin fiziksel ve sosyal çevresini temsil eder. Nehir yan duvarları ve tabanını kalınlaştırarak veya incelterek çevrenin kişinin yaşam akışını üzerindeki etkisi ifade edilir. Nehir tabanı ve duvarlar kişinin sosyal ve fiziksel çevresini temsil eder. Kişinin yaşadığı yer, hayatındaki insanlar, içinde bulunduğu kültür yapısı gibi faktörler bu nehrin taban ve duvarlarını şekillendirir. Sosyal çevre açısından rahatsız edici veya uyumsuzluk hali; yaşam enerjisinin veya suyun akışının zayıfladığı kavram içerisinde tanımlanır ${ }^{41}$. Bireyin hayatının itici gücü; bir nehrin yatağında bulunan temas ettiği ve ilişki içinde olduğu bütün elementlere benzeyen yani sosyal çerçeveyi paylaşan diğer insanlarla bağlantılıdır. Duvarları veya tabanı daha kalın yapmak, su akışını tehlikeye atarken, daha ince yapmak bireyi teşvik eder. Su, bireylerin yaşam enerjisinin akışını sembolü olan alanın büyüklüğü ile engeller arasındaki boşlukta akmaktadır. Kawa modelinin avantajı, nehir yan duvarlarını/tabanını, kayaları ve suyu birbirine uygun şekilde yerleştirerek çevre, engeller ve yaşam akışı/enerjisi arasındaki ilişkileri göstermesidir42. İnsan yaşamının; çevre ve yaşam koşulları ile sınırlandırılıp şekillendirildiği gibi, bir nehir boyunca akan su da kayalara, nehrin kenarına, nehirdeki enkaza ve nehrin içeriğini oluşturan diğer tüm ögelere dokunur. Yapllan bir çalışma, Kawa modelinin şiddet mağduru bireylerin iyileşme sürecine rehberlik etmesi için çevrenin tüm yönlerinin göz önünde bulundurulması gerektiğini bildirmiştir43.

\section{Okupasyonel Adaptasyon Modeli}

Okupasyonel adaptasyon modeli, bireylerin çevrelerine uyum sağlayarak tepki verme sürecini kavramsallaştırmak için bir çerçeve sağlamayı amaçlar. Adaptasyon, bireyin okupasyonlarında bir zorlukla karşılaştığında çevreye verdiği tepkideki değişiklik olarak tanımlanır44. Model, bireylerin ustalığı arzulaması ve çevrelerin bunu talep etmesine odaklanarak bu iki yapının karşılıklı etkileşimini yansıtır. Model, bireyin çevreyle uyumu arttıkça bağımsızlığının da arttığını vurgulamaktadır45. Modelde kişi ve çevre faktörleri önemli olup ergoterapistlerin çerçeve oluşturmasını sağlar. Kişi kavramı sensorimotor, bilişsel ve psikososyal olmak üzere 3 sistemden oluşur. Kişinin bu sistemleri genetik, çevresel ve deneyimsel alt sistemleri ile oluşturulur. Okupasyonel çevre kavramı okupasyonel yanıt için önemlidir. İş, oyun, serbest zaman ve kendine bakım okupasyonları olup çevre ise fiziksel, sosyal ve kültürel çevreden oluşmaktadır ${ }^{46}$.

\section{İnsan Performansı Ekoloji Modeli}

Ekoloji terimi, bir organizma ve çevresi arasındaki etkileşimi anlamakla ilgilidir47. Çevre psikolojisinde bireyler yakın fiziksel çevre ile karşılıklı etkileşim halindedir ve çevre bireyin davranışlarını etkilerken birey davranışlarını çevreye göre değiştirir48. Model üç temel yapıdan oluşmaktadır: kişi, görev ve bağlam 49. Bu yapılar arasındaki ilişki performansı anlamaya yardımcı olur. Kişi ve bağlam arasındaki etkileşim ise davranışı ve performansı etkilemektedir. Model çevresel yetkinliği tanımlarken bireyin hedeflerine ulaşmak ve tecrübesini geliştirmek için çevreyi kullanma bilgisi, becerisi ve güveni ifadesini kullanmıştır. Modelde çevre insan gelişimi ve performansın anlaşılmasında temel kabul edilir ve davranışın, mikrosistem, mezosistem ve ekosistem olan üç çevre seviyesinden etkilendiği belirtilir ${ }^{\circ}$. Modele dayalı bir müdahale olarak 
alışveriş aktivitesinin şizofrenili bireylerin becerileri geliştirip geliştirmediğini inceleyen bir araştırmada, görevi ve çevreyi organize eden ve basitleştiren stratejilerin kullanılması bilişsel bozuklukları telafi etmede kullanılabilir olduğu bildirilmiştir51.

\section{Bilişsel Algısal Model}

Bilişsel algısal yaklaşım beynin bilgileri işlemleme yeteneği ile ilgilidir. Bu model bilişsel algısal süreçteki bozukluğun okupasyonel performansı nasıl etkilediği üzerine odaklanır. Bilişsel problemlerin görev ve çevre koşullarına bağlı olduğunu ifade eder52. Fonksiyonel bilişsel yaklaşımları içeren ve ergoterapistler tarafından kullanılan Toglia'nın Dinamik Etkileşimsel Modeli çevresel faktörlerin okupasyonel performansı (fiziksel, kültürel çevre, sosyal etkileşim vb.) etkilediği düşünülür. Model özellikle kava travması ve inme geçirmiş bireyler olmak üzere diğer bilişsel bozukluğa sahip bireyler için de kullanılmaktadır. Bilişsel problemlerin okupasyonel performans alanları ve rollerini etkilediği için aktivitelerin farklı ortamlarda oluşturulmasını önermektedir53.

Şekil 6. Toglia'nın Dinamik Etkileşimsel Modeli

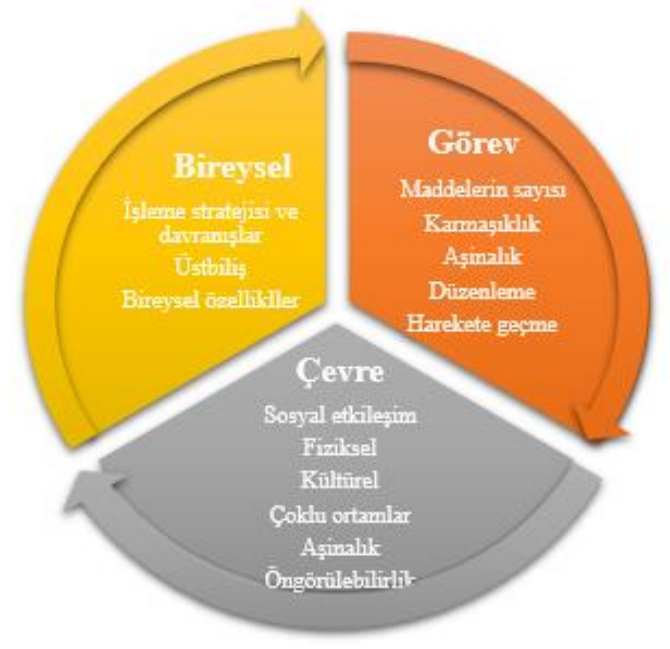

\section{Duyu Bütünleme Modeli}

Merkezi sinir sisteminin gelişimi genetik ve çevresel faktörlerin etkileşimi ile gerçekleşir. Beyinde sinaptik bağlantıların oluşması için, duyusal sistemler tarafından alınan çevresel girdiler merkezi sinir sisteminin gelişimini önemli derecede etkilemektedir54. Bu durumda devreye giren duyu bütünleme kavramı "vücudumuzdan ve çevremizden aldığımız duyu bilgilerinin kullanım için organize edilmesi" olarak tanımlanmaktadır55. Duyu Bütünleme Modeli ise duyusal bilgiyi düzenleme ile öğrenme ve uygulamada kullanma yeteneğinin, çocuğun normal çevresel zorluklarla etkileşime girmesiyle gelişebileceğini önermektedir. Duyu bütünleme modeline göre oyun, duyusal motor davranışın gerçekleştiği en büyük alandır, çünkü çocuklar genellikle bedenlerine ve dünyaya adapte olmayı ve öğrenmeyi oyun vasıtasıyla geliştirir56.

\section{Nöroplastisite ve Çevre}

Nöroplastisite, sinir sisteminin iç veya dış uyaranlara yanıt olarak kimyasını, yapısını ve işlevini değiştirme kapasitesini ifade eder57. İnsan beynini değişim ve gelişime açık tutan temel unsurlardan biri deneyimdir. Deneyim, birey veya çevre hakkında genellikle somut olarak öngörülemeyen ve bu nedenle genetik olarak kodlanamayan bilgiler sağlar ${ }^{5}$. Nöroplastisite yeni 
durumlara daha iyi uyum sağlamak amacı ile beynin değişme, yeniden modelleme ve yeniden düzenleme yeteneği olarak tanımlanabilir59. Nöroplastisite mekanizmaları, çevresel, davranışsal veya sinirsel süreçler ve hastalık tarafından aktive edilir, hareketle ilişkili motor ve bilişsel öğrenmeyi desteklerler57. Davranışsal deneyim ile değişen nöronların yapısal özellikleriyle birlikte beynin yaşam boyu deneyime bağlı plastisite kapasitesi, yeni ortamlara ve ortamdaki değişikliklere uyum sağlar60,61. Deneyimin etkin olduğu sürecin devamlılığı ve davranış üzerindeki görülen etkileri, duyusal uyaranların zenginliği, deneyimlerin kalitesi ve miktarı ile orantılı olarak değişkenlik gösterir62. Revize edilmiş duyusal deneyim protokollerine dayalı çalışmalara paralel olarak, çevresel deneyimin uygun nöral bağlantıların geliştirilmesi, iyileştirilmesi ve bakımı üzerindeki etkisinin anlaşılmasıyla ilgili ilerleme özellikle çevresel kalite ve yoğunluğunu arttırmaya yönelik paradigmalar tarafından mümkün olmuştur63.

Zenginleştirilmiş fiziksel, sosyal ve bilişsel uyaranların bulunduğu bir ortamda yetiştirilen farelerde, plastisite ve beyin üzerinde uzun süreli etkileri gözlemlenmiştir62. Çevresel zenginleştirme karmaşık, cansız ve sosyal uyaranların bir kombinasyonu olarak tanımlanır 64 . Çevresel zenginleştirme ile intrakortikal inhibisyonun azalmasının görsel kortekste plastisitenin artmasına neden olduğu tespit edilmiştir65. Zenginleştirilmiş çevre, fiziksel ve bilişsel içerikli okupasyonların yanı sıra sosyal etkileşimi destekleyen ve teşvik eden bir ortam sağlamaktadır ${ }^{66}$. Ergoterapist mevcut olanı koruma ve optimize etmeyi hedeflerken, çevresel zenginleştirmenin fonksiyonel sonucu önemli ölçüde iyileştirdiği görülmüş ve dentritik dallanma ve diken sayısında artış gözlemlenmiştir67. Doğru uyaranlarla planlanmış bir çevre faktörü adaptif nöroplastisiteyi yönlendiren ve bireylerin benzersiz özelliklerine göre uyarlanmış etkili rehabilitasyon hakkında daha fazla bilgi sağlayabilme potansiyeli olduğu için iyileşme sürecinde rolü olacaktır68. Çünkü doğru bir çevre faktörü danışanın motivasyonu, kendini ifade etmesi ve dönüşümüne katkı sağlayabilir. Sosyal açıdan zenginleştirilmiş çevre ise daha fazla bilgiyi konsolide etme ve saklama yeteneği sağlayarak görev odaklı okupasyonları öğrenmeyi desteklemektedir ${ }^{69,70}$. Duyusal yoksunluğa neden olan yaşam şartlarında, genel yaşam kalitesini düşürebilecek ve hareketsizliğe neden olabilecek olumsuz davranışsal semptomları şiddetlendirdiği bulunmuştur ${ }^{19}$. Bir araştırmada duyusal yoksunluğun aksine nitelikli çevresel uyaranların beyin gelişimi ve plastisite üzerinde anlamlı etkisi olduğu gösterilmiştir64. Farklı bir açıdan ele alındığında "zenginleştirme" standart veya tek tip bir program için bir terimden ziyade göreceli bir kavramdır. Zenginleştirilmiş ortamlarla ilgili çalışmalar genellikle artan çevresel uyaranların plastisite ve beyin gelişimi üzerindeki etkilerinin aracılık ettiği düşünülen fonksiyon kazanımlarına odaklanır64. Fakat terapistin danışanı kapsamlı değerlendirme tanıma süreciyle birlikte doğru uyaranları barındıran bir dizayn yapabilmesi kabiliyeti de gerektiren bir donanımdır. Yanlış bir yol haritası çizilmesi ve buna bağlı veya danışanın tanısıyla ilişkili bir yoksunluk, duyusal sistemlerin gelişimini engelleyebilir ve deneyimden beklenen plastisitenin tipik zamansal pencerelerini uzatabilir ${ }^{71}$.

\section{Sonuç ve Öneriler}

Ergoterapi literatürü, çevrenin okupasyonel performans için önemini kabul eder ${ }^{12,16,72}$. Ergoterapinin amacı ise bireyin okupasyonel katılımını desteklemek için çevredeki koşulları uygun hale getirmektir73. Uygulamada ergoterapistlerin bireylerin yakın çevresine odaklanarak çevrenin okupasyonel performans üzerindeki önemli etkisini tam olarak belirlemesi gerekir ${ }^{12}$. Bütüncül olarak süreci anlamlı kılan bileşenlerden biri olan ve sağllk ve iyi oluş halinin sürdürülebilirliğinin bir parçası olan çevre faktörüdür. Okupasyonlar ve sosyal katılım noktasında, nöroplastisite açısından değerlendirme sürecinde kişi ve çevrenin baskınlığ yansımaktadır. Ergoterapide modeller, terapistlere bir protokol çerçevesi sunarken, görüldüğü gibi çevre faktörünün de değerlendirme sürecinde teşkil ettiği alan ve sürecin bir parçası olması 
noktasındaki önemine dikkat çekmektedir. Bir terapi ortamı okupasyonlara katılım için firsatlar sunuyorsa, rehabilitasyon ortamını danışanın fonksiyon temelli hedefleri ile uyumlu hale getirirken okupasyon temelli uygulamayı desteklemektedir74. Bir birey bulunduğu çevre içinde rahat olduğu ölçüde deneyimlere uyum ve katılım sağladığı ifade edilmektedir75. Doğru uyaran ve materyaller ile zenginleştirilmiş çevre faktörü ile amaç, çoklu duyusal uyaranların, anlamlı okupasyonlara teşvik, gelişmiş sosyal etkileşimler ve kendiliğinden keşif davranışını ortaya çıkaracak bir kombinasyon sağlayarak yaşam kalitesini iyileştirmektir. Kişiye özgü terapi ve tedavi programlarının, bireysel özellikler, psikolojik durum ve hastalıkları göz önünde bulundurarak planlanması gerekir. Bireysel özelliklerin üzerine eğilmek, bir danışanın yapmak istediklerini ve ilgi alanlarını tespit etmek terapi sürecinin etkinliğini arttırabilir. Bu sayede anlamlı kortikal plastisite görülme imkânı artabilir. Bu bağlamda ergoterapi modellerinde de gerekli önemin gösterildiği çevre faktörü, süreci verimli ve anlamlı kılmaktadır.

Uzmanlar arasında zenginleştirilmiş ortamların tanımı üzerinde anlaşmaya varılmamış olması bir çeşit ihmal problemidir. Çünkü "zenginleştirilmiş ortamlara" atfedilen etkiler, tedavinin herhangi bir yönüne kesin olarak atfedilemez ve çalışmalar değişen programlar kullandığında sonuçların tekrarını tespit etmek zordur. Sinir sistemi adaptif nöroplastisitesini optimize etmek için en iyi müdahalelerin nasıl uygulanacağı ve nihayetinde uygun fonksiyonel iyileşmeye yol açan öğrenme hakkında daha detaylı araştırmalara ihtiyaç duyulmaktadır.

\section{KAYNAKLAR}

1. Law MC, Baum CM, Baptiste S. eds. Occupation-based practice: Fostering performance and participation. Slack Incorporated; 2002.

2. Cherylin Lew O. Occupational therapy's perspective on the use of environments and contexts to support health and participation in occupations. The American Journal of Occupational Therapy. 2010;64(6):S57.

3. Kiernat JM. Environment: The hidden modality. Physical \& Occupational Therapy in Geriatrics. 1982;2(1):3-12.

4. Hubbard IJ, Parsons MW, Neilson C, Carey LM. Task-specific training: Evidence for and translation to clinical practice. Occupational Therapy International. 2009;16(3-4):175-189.

5. Hecox R, Roach KE, DasVarma JM, Giraud JE, Davis CM, Neulen K. Functional independence measurement (FIM) of patients receiving easy s treeta-a retrospective study. Physical \& Occupational Therapy in Geriatrics. 1994;12(3):17-31.

6. American Occupational Therapy Association. Occupational Therapy Practice Framework: Domain Et Process. 2020.

7. McClusky JF. Creating engaging experiences for rehabilitation. Topics in Stroke Rehabilitation. 2008;15(2):80-86.

8. Dunn W. The sensations of everyday life: empirical, theoretical, and pragmatic considerations. American Journal of Occupational Therapy. 2001;55(6):608-620.

9. Furr RM, Funder DC. Persons, situations, and person-situation interactions. Handbook of Personality: Theory and Research. 2018;4.

10. Din PCB. International classification of functioning, disability and health. 2001.

11. Rebeiro KL. Enabling occupation: The importance of an affirming environment. Canadian Journal of Occupational Therapy. 2001;68(2):80-89.

12. Law M. The environment: A Focus For Occupational Therapy. Los Angeles, CA:SAGE Publications Sage CA; 1991. 
13. Law M. Participation in the occupations of everyday life. American Journal of Occupational Therapy. 2002;56(6):640-649.

14. Rogers S. Occupation-based intervention in medical-based settings. OT Practice. 2007;12(15):10.

15. Coster W, Law M, Bedell G, Khetani M, Cousins M, Teplicky R. Development of the participation and environment measure for children and youth: Conceptual basis. Disability and Rehabilitation. 2012; 34:3, 238-246, DOI: 10.3109/09638288.2011.603017.

16. Law M, Cooper B, Strong S, Stewart D, Rigby P, Letts L. The person-environmentoccupation model: A transactive approach to occupational performance. Canadian Journal of Occupational Therapy. 1996;63(1):9-23.

17. Broome K, McKenna K, Fleming J, Worrall L. Bus use and older people: A literature review applying the person-environment-occupation model in macro practice. Scandinavian Journal of Occupational Therapy. 2009;16(1):3-12.

18. Strong S, Rigby P, Stewart D, Law M, Letts L, Cooper B. Application of the personenvironment-occupation model: A practical tool. Canadian Journal of Occupational Therapy. 1999;66(3):122-133.

19. Degenholtz HB, Miller MJ, Kane RA, Cutler LJ, Kane RL. Developing a typology of nursing home environments. Journal of Housing for the Elderly. 2006;20(1-2):5-30.

20. Wong C, Leland NE. Applying the Person-Environment-Occupation Model to Improve Dementia Care. London, UK: OT Practice; 2018.

21. Maseda A, Sanchez A, Marante MP, Gonzalez-Abraldes I, Bujan A, Millan-Calenti JC. Effects of multisensory stimulation on a sample of institutionalized elderly people with dementia diagnosis: A controlled longitudinal trial. American Journal of Alzheimer's Disease \& Other Dementias. 2014;29(5):463-473.

22. Milev RV, Kellar T, McLean M, et al. Multisensory stimulation for elderly with dementia: A 24-week single-blind randomized controlled pilot study. American Journal of Alzheimer's Disease \& Other Dementias. 2008;23(4):372-376.

23. Bauer M, Nay R. Family and staff partnerships in long-term care: A review of the literature. Journal of Gerontological Nursing. 2003;29(10):46-53.

24. Gitlin LN, Corcoran M. Expanding caregiver ability to use environmental solutions for problems of bathing and incontinence in the elderly with dementia. Technology and Disability. 1993;2(1):12-22.

25. Ho ECM, Siu AMH. Occupational therapy practice in sleep management: A review of conceptual models and research evidence." Occupational therapy international. 2018: 8637498.

26. Christiansen CH, Baum CM, Bass-Haugen J. Comparing the languages of: The ICF, the PEOP model, the AOTA practice framework. Occupational therapy: performance, participation \& well being. 3rd edition. Thorofare New Jersey: Slack Incorporated; 2005.

27. Christiansen C, ed. Occupational therapy: Performance, Participation, and Well-being. Slack Incorporated; 2005.

28. Kielhofner G, Burke JP. A model of human occupation, part 1. conceptual framework and content. American Journal of Occupational Therapy. 1980;34(9):572-581.

29. Lee J, Kielhofner G. Vocational intervention based on the model of human occupation: A review of evidence. Scandinavian Journal of Occupational Therapy. 2010;17(3):177-190.

30. Lee SW, Taylor R, Kielhofner G, Fisher G. Theory use in practice: A national survey of therapists who use the Model of Human Occupation. American Journal of Occupational Therapy. 2008;62(1):106-117. 
31. Kielhofner G. A model of human occupation, Part 3. Bening and vicious cycles. American Journal of Occupational Therapy. 1980;34(11):731-737.

32. Kielhofner G. A Model of Human Occupation: Theory and Application. Lippincott Williams \& Wilkins, 2002.

33. Jo YJ, Kim H. Effects of the model of human occupation-based home modifications on the time use, occupational participation and activity limitation in people with disabilities: a pilot randomized controlled trial. Disability and Rehabilitation: Assistive Technology. 2020. DOI: 10.1080/17483107.2020.1768306.

34. Kielhofner G, Braveman B, Fogg L, Levin M. A controlled study of services to enhance productive participation among people with HIV/AIDS. The American Journal of Occupational Therapy. 2008;62(1):36-45.

35. Townsend EA, Polatajko HJ. Advancing an occupational therapy vision for health, wellbeing, and justice through occupation. CAOT Publications, Ottawa; 2007.

36. Wong SR, Fisher G. Comparing and using occupation-focused models. Occupational Therapy in Health Care. 2015;29(3):297-315.

37. Law M, Baptiste S, McColl MA, Opzoomer A, Polatajko H, Pollock N. The Canadian occupational performance measure: An outcome measurement protocol for occupational therapy. Can J Occup Ther. 1990;57:82-87.

38. Nossum R, Johansen AE, Kjeken I. Occupational problems and barriers reported by individuals with obesity. Scandinavian Journal of Occupational Therapy . 2018;25:2, 136144, DOI: $10.1080 / 11038128.2017 .1279211$

39. Kronenberg F, Pollard N, Sakellariou D. Occupational therapies without borders- volume 2 E-Book: Towards an ecology of occupation-based practice. Elsevier Health Sciences; 2011.

40. Iwama MK. The Kawa model: Culturally Relevant Occupational Therapy. Elsevier Health Sciences; 2006.

41. Iwama MK, Thomson NA, Macdonald RM, Iwama MK, Thomson NA, Macdonald RM. The Kawa model: The power of culturally responsive occupational therapy. Disability and Rehabilitation, 2009;31(14):1125-1135.

42. Wada M. Strengthening the Kawa model: Japanese perspectives on person, occupation, and environment. Canadian Journal of Occupational Therapy. 2011;78(4):230-236.

43. McCullough $\mathrm{P}$, Weher K. Occupational therapy program for women residing in domestic violence shelters. Occupational Therapy Capstones. 2020; 460. https://commons.und.edu/ot-grad/460.

44. Christiansen C, Baum CM. Occupational Therapy: Enabling Function and Well-being. Slack; 1997.

45. Stead J. Using occupational therapy models in practice. British Journal of Occupational Therapy. 2012;75(6):300-301.

46. Bumin G, Akel B, Öksüz Ç. Ergoterapi Teoriler, Modeller ve Uygulama Yaklaşımları. Ankara: Hipokrat Yayıncılık; 2019.

47. Dunn W, Brown C, McGuigan A. The ecology of human performance: A framework for considering the effect of context. American Journal of Occupational Therapy. 1994;48(7):595-607.

48. Howe MC, Briggs AK. Ecological systems model for occupational therapy. American Journal of Occupational Therapy. 1982;36(5):322-327.

49. Dunn, W., Brown, C., \& McGuigan, A. . The ecology of human performance: A framework for considering the effect of context. The American Journal of Occupational Therapy,1994;48(7):595-607. 
50. Richard L, Gauvin L, Raine K. Ecological models revisited: Their uses and evolution in health promotion over two decades. Annual Review of Public Health. 2011;32:307-326.

51. Brown C, Rempfer M, Hamera, E. Teaching grocery shopping skills to people with schizophrenia. OTJR: Occupation, Participation and Health. 2002;22:90S-91S.

52. Hartman-Maeir A, Katz N, Baum CM. Cognitive functional evaluation (CFE) process for individuals with suspected cognitive disabilities. Occupational Therapy in Health Care. 2009;23(1):1-23.

53. Toglia JP. The dynamic interactional model of cognition in cognitive rehabilitation. In: Katz N ed. Cognition, ccupation, and Participation Across The Life Span: Neuroscience, Neurorehabilitation, and Models of Intervention in Occupational Therapy. American Occupational Therapy Association; 2011.

54. Ayres AJ, Robbins J. What is Sensory Integration. In: Ayres AJ ed, Robbins J. Sensory Integration and The Child: Understanding Hidden Sensory Challenges. Western Psychological Services; 2005.

55. Bundy AC, Shelly JL. Theoretical Construction. In: Bundy AC, Shelly JL eds. Sensory Integration: Theory and Practice. FA Davis. 2019.

56. Bundy AC. Play theory and sensory integration. In: Bundy AC, Lane SJ, Murray EA, eds. Sensory integration: Theory and practice. 2nd ed. Philadelphia: 2002: 227-240.

57. Cramer SC, Sur M, Dobkin BH. Harnessing neuroplasticity for clinical applications. Brain. 2011;134(6):1591-1609.

58. Knudsen EI. Sensitive periods in the development of the brain and behavior. Journal of Cognitive Neuroscience. 2004;16(8):1412-1425.

59. Demarin V, Morovic S. Neuroplasticity. Periodicum Biologorum. 2014;116(2):209-211.

6o. Kleim JA, Jones TA. Principles of experience-dependent neural plasticity: Implications for rehabilitation after brain damage. Journal of Speech, Language, and Hearing Research. 2008; 51(1).

61. Alwis DS, Rajan R. Environmental enrichment and the sensory brain: The role of enrichment in remediating brain injury. Frontiers in Systems Neuroscience. 2014;8:156.

62. Greifzu F, Pielecka-Fortuna J, Kalogeraki E. Environmental enrichment extends ocular dominance plasticity into adulthood and protects from stroke-induced impairments of plasticity. Proceedings of the National Academy of Sciences. 2014;111(3):1150-1155.

63. Rosenzweig MR, Bennett EL, Hebert M, Morimoto H. Social grouping cannot account for cerebral effects of enriched environments. Brain Research. 1978;153(3):563-576.

64. Baroncelli L, Braschi C, Spolidoro M, Begenisic T, Sale A, Maffei L. Nurturing brain plasticity: Impact of environmental enrichment. Cell Death \& Differentiation. 2010;17(7):1092-1103.

65. Sale A, Vetencourt JFM, Medini P. Environmental enrichment in adulthood promotes amblyopia recovery through a reduction of intracortical inhibition. Nature Neuroscience. 2007;10(6):679-681.

66. Bernhardt J, Dewey H, Thrift A, Donnan G. Inactive and alone: Physical activity within the first 14 days of acute stroke unit care. Stroke. 2004;35(4):1005-1009.

67. Johansson B. Environmental influence on recovery after brain lesions-experimental and clinical data. Journal of Rehabilitation Medicine-Supplements. 2003(41):11-16.

68. Kloos A, Gomes-Osman J, Boyd L. Harnessing neuroplasticity for functional recovery. Journal of Neurologic Physical Therapy. 2020;44(2):119-120.

69. Gardner EB, Boitano JJ, Mancino NS, D'Amico DP, Gardner EL. Environmental enrichment and deprivation: Effects on learning, memory and exploration. Physiology \& Behavior. 1975;14(3):321-327. 
70. Harati H, Barbelivien A, Herbeaux K, et al. Lifelong environmental enrichment in rats: Impact on emotional behavior, spatial memory vividness, and cholinergic neurons over the lifespan. Age. 2013;35(4):1027-1043.

71. Ball NJ, Mercado III E, Orduña I. Enriched environments as a potential treatment for developmental disorders: A critical assessment. Frontiers in Psychology. 2019;10:466.

72. Dunn W, Brown C, McGuigan A. The ecology of human performance: A framework for considering the effect of context. American Journal of Occupational Therapy. 1994;48(7):595-607.

73. Kielhofner G, Forsyth K, Kielhofner G. The process of change in therapy. In: Kielhofner G ed. A Model of Human Occupation: Theory and Application. 2002:296-308.

74. American Occupational Therapy Association. "Workgroup on the implementation of occupation-based practice. " Report to the Executive Board on The Implementation of Occupation-based Practice. Retrieved. 2014;14:4-36.

75. Lawton MP, Nahemow L. Ecology and the aging process. In: Eisdorfer C, Lawton MP, eds. Psychology of Adult Development and Aging. Washington, DC: American Psychological Association; 1973:619-74. 